\title{
Hospital-based pandemic preparedness and response: institutional outbreak management and strategies adhered to prevent a surge
}

\author{
Anuji Gamage", Nayana Fernando, Aindralal Balasuriya \\ Department of Public Health and Family Medicine, Faculty of Medicine, General Sir John Kotelawala Defence \\ University, Ratmalana, Sri Lanka
}

"Correspondence: anujigamage@gmail.com

https://orcid.org/0000-0002-4713-9283

DOI: https://doi.org/10.4038/jccpsl.v26i5.8326

Received on 9 May 2020

Accepted on 23 May 2020

\begin{abstract}
Summary
The University Hospital of Kotelawala Defence University (UH-KDU) situated at Werahera, Boralesgamuwa is a state-of-the-art hospital with approximately 704 beds and consists of all specialties including laboratories, cath-lab for complex cardiac interventions, an oncology unit and intensive care units. The UH-KDU is the training hospital of medical and allied health undergraduates of General Sir John Kotelawala Defence University (KDU), Ratmalana. In this narrative report, we describe the public health measures adhered to and taken to manage an institutional outbreak in order to prevent a surge.
\end{abstract}

\section{Public health response and its impact}

Diseases with pandemic potential are public health concerns due to mutual interdependence of the global community and the ability to cause social and economic disruption due to rapid spread (1). It is a norm that during outbreak situations, preventive health experts work side-by-side with the clinicians at curative care institutions to control the incident (2). Control of institutional outbreaks includes inspection of the premises, case detection and contact tracing with the support of all relevant stakeholders. Institutional activities should link with strong wellplaced public health services in the country and the support provided by the Epidemiology Unit, Colombo.
Two employees at UH-KDU tested positive for COVID-19 and the institution responded promptly to prevent the situation escalating to a progressive calamity. The UH-KDU initiated pandemic preparedness activities on 26 January 2020, mainly confined to clinical management of the patients and prevention of nosocomial infection. However, at this point, there were no public health activities included. Subsequently,

the need for public health expertise during the crisis was identified followed by a formal invitation extended to them on 24 March 2020 to initiate on-site outbreak management. 


\section{Outbreak management: Initial response}

Prompt identification of cases and contacts is the initial and the foremost step in handling any infectious disease. Hence, as two employees tested positive for COVID-19, the priority was to track additional cases and contacts and place them on quarantine. Also, it was essential to track the exposure history of the two index cases. As this was done on 24 March 2020, the team did not have a circular from the Ministry of Health nor clear guidance on what "a confirmed COVID-19 case" or a "contact" is. Hence, details of all the staff exposed to the two positive employees irrespective of time and distance were gathered. As this was done without a proper case definition, the list prepared on the first day was exhaustive which impinged on the fact that the institution had to function with adequate staff to continue delivering the services. A search for guidelines was done, and thereafter we adhered to the WHO's Interim Guidelines on Risk Assessment and Management of Exposure of Healthcare Workers in the Context of COVID-19 (3) and the case definitions were discussed and further confirmed by the Epidemiology Unit. This facilitated us to categorise the employees who claimed an unprotected exposure to a patient as 'high', 'medium' and 'low' risk. Subsequently, a shorter list was prepared by the end of second day, and work restriction and preventive measures were based on these risk categories. As the delegated authority was the medical officer of health $(\mathrm{MOH})$, they were contacted, and the updated information was shared regularly.

Some employees were home quarantined and some within the UH-KDU. The main reason for the latter was the stigma resulting in denial of boarding/ lodging places from owners. Procedures for those quarantined within the premises such as close monitoring and reporting, referral and isolation if symptomatic, and practice of infection control by medical, nursing and supporting staff were established. The information of home quarantined staff was shared with relevant MOHs. This facilitated the field activities conducted by the area public health inspectors. Other necessary tasks like health education and training were carried out for the staff, which included sessions, audio-visual aids, leaflets, posters and stickers. The Epidemiology Unit circulars and guidelines were adhered to and communicated to all authorities regularly.

By the end of the first week, we had established a fully functional public health operational cell at $\mathrm{UH}^{-}$ KDU with three consultants in community medicine and two medical officers. The hospital staff visited the premises for preventive health advice, disease notification related issues while research related to COVID too was coordinated. A log book was maintained to monitor each day's progression.
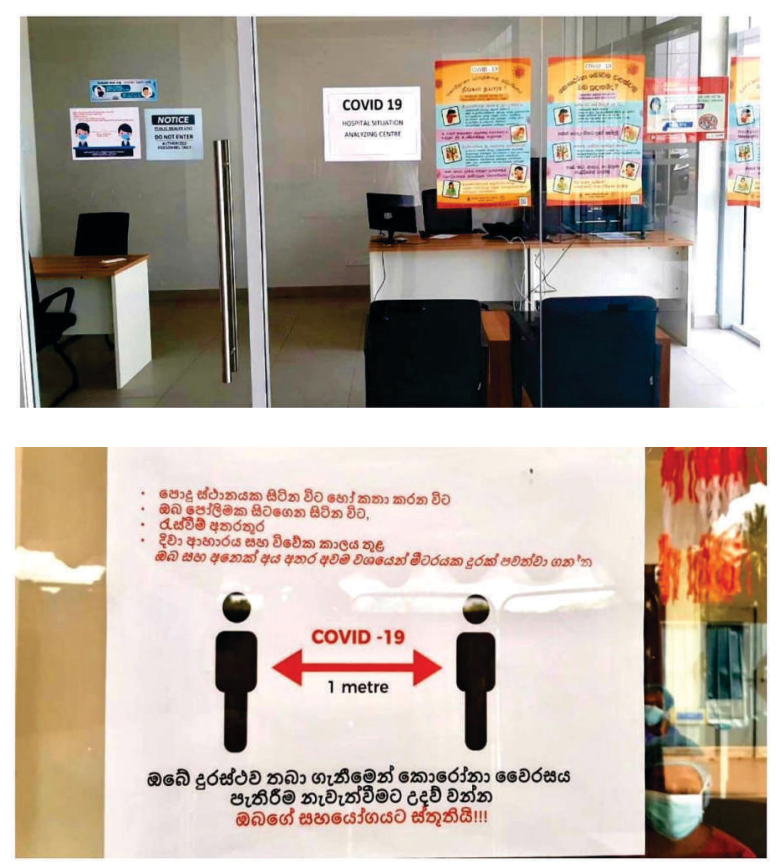

Figure 1: The fully functional public health operational cell at UH-KDU

\section{Outbreak management: Surge plan}

During this epidemic at UH-KDU, we were cautious and prepared for a 1 . second wave, 2. surge, 3 . maintaining quarantine facilities and 4 . a pandemic preparedness plan for resumption of academic activities. A comprehensive all-hazards disaster response (4) and preparedness plan inclusive of infection control, health education and awareness raising, coordination of hospital capacity (guidelines, personal and protective equipment supply, details of patients and staff), surveillance (e.g. influenza like illness and severe acute respiratory illness), risk communication (internal and external communication systems) and a surge plan (5) was deemed necessary. Additionally, a workplace plan 
for "exiting lock down" with recommendations was prepared. It was also necessary to form COVID-19 Planning and Response Committees at the UH-KDU and the University at Ratmalana to discuss the weekly progress and decision making.

\section{Challenges}

Quarantine is the separation and restriction of movement or activities of persons who are not ill but believed to have been exposed to the infection to see if they become sick and to prevent transmission of diseases (6). A majority of the healthcare workers were boarded or had rented premises close to the hospital. They faced stigma related to COVID-19, which included social avoidance and denial of housing, especially after the media disclosed detection of cases at the UH-KDU. This was managed by raising awareness of the community about COVID-19 without increasing fear, and by maintaining privacy and confidentiality of anyone who were subjected to contact tracing. This was successfully handled with the collaboration of the $\mathrm{MOH}$ staff who visited the places and took corrective measures.

A circular which recommends establishment of an operational cell at hospitals exists, but it does not include public health staff or the channels of communication. Terms of References were not available on activities of such a unit, which were limitations as observed in this outbreak management (7).

Preventive action overlapped with infection control and patient management activities. This illustrated that a pandemic preparedness team should include personnel from all these areas and as healthcare workers we should change the clinically oriented mindset of an infectious disease to a problem solving, outbreak management approach which is achieved by a team in which a public health specialist too plays a role.

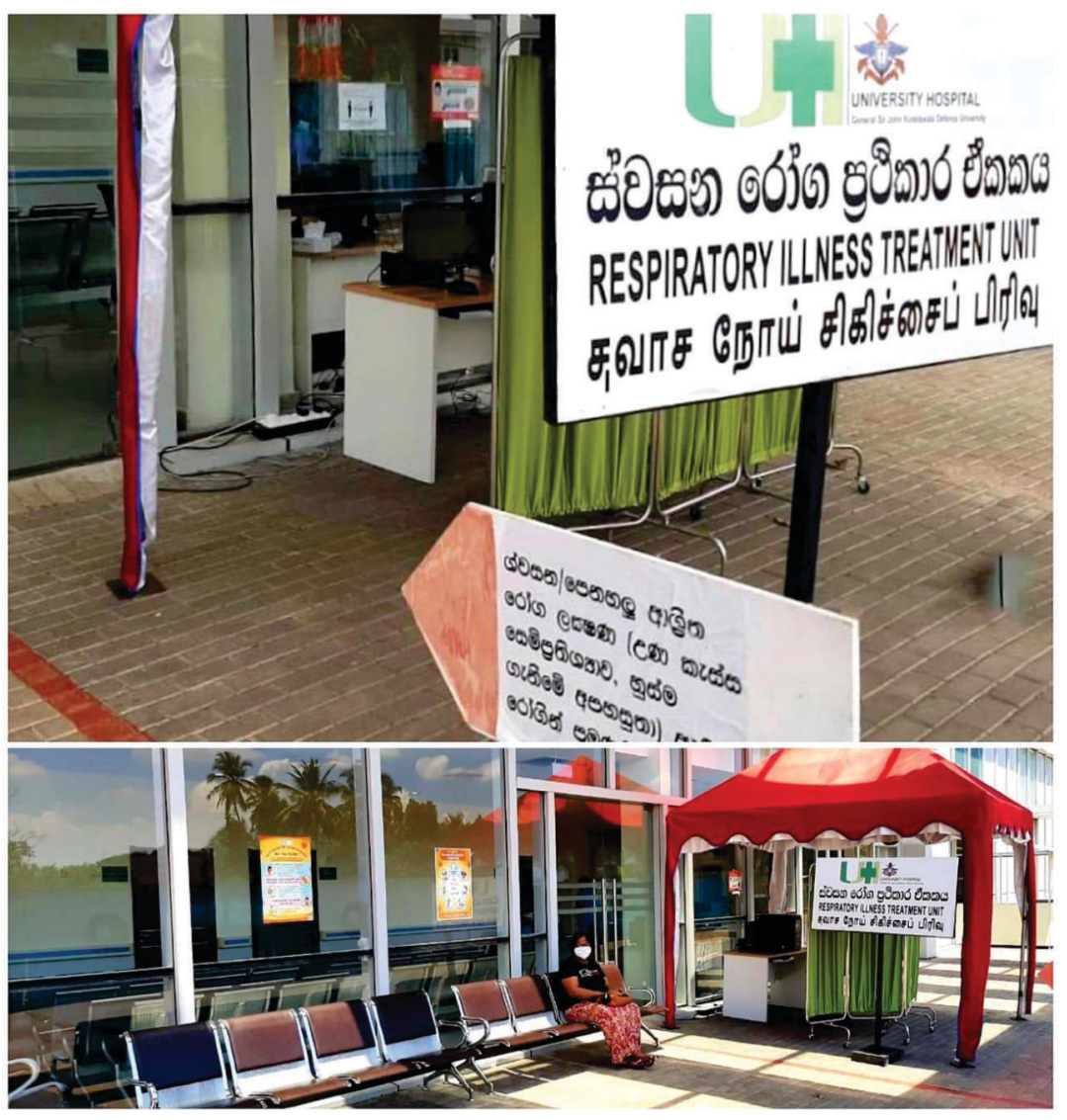

Figure 2: Respiratory illness screening and surveillance at UH-KDU 


\section{Future implications}

The threat of a pandemic will linger until it is eliminated globally; until such time, all activities related to outbreak response should continue with regular review to reflect what has worked and necessary adjustments done as needed. Heightened surveillance, health education, case detection, quarantine and most importantly coordination of all hospital related activities are to be continued with contribution from all stakeholders, and therefore teamwork is crucial in institutional outbreak response. This should be done proactively before the occurrence of a crisis with the involvement of public health expertise when available.

On two occasions, rumours and messages were shared in mass media and social media related to the COVID-19 outbreak at UH-KDU. This is harmful for the image of the institution; thus a rumour monitoring, identification, verification and management plan needs to be developed and implemented.

This is an example of best practices in collaboration, where a university hospital incorporated public health specialists to control a crisis situation via recognition of the community preventive service provision, public health emergency preparedness and leadership skills of the public health specialists (8). The leadership of the institute that engaged the relevant specialists from the initial stage onwards to plan, organize, administer, manage, evaluate, and analyse the outbreak is noteworthy. Our experience further reiterates the fact that public health specialists should be placed in hospitals to prevent disease, promote health and to carry out important public health activities within the institution.

\section{Author Declaration}

Author contributions: All authors were involved in planning of the article. AUG drafted the manuscript and all authors were involved in editing it. All authors approved the final manuscript.

\section{References}

1. Madhav N, Oppenheim B, Gallivan M, Mulembakani P, Rubin E, Wolfe N. Pandemics: risks, impacts and mitigation. In: Disease Control Priorities ( $3^{\text {rd }}$ edition): Volume 9, Disease Control Priorities, edited by Jamison DT, Gelband H, Horton S, Jha P, Laxminarayan R, Mock CN, Nugent R. Washington, DC: World Bank, 2017.

2. Lundberg GD. Might COVID-19 meld public health with clinical medicine? Commentary. Medscape, 4 April 2020. Available from: at https://www. medscape.com/viewarticle/928140.

3. WHO. Risk assessment and management of exposure of health care workers in the context of COVID-19: Interim Guidance, 19 March 2020. Geneva: World Health organization, 2020. Available from : https://apps.who.int/iris/ bitstream/handle/10665/ 331496/WHO-2019-nCov-HCW_risk_assessment2020.2-eng. pdf? sequence $=1 \&$ is Allowed $=\mathrm{y}$.

4. University Hospital of General Sir John Kotelawala Defence University (UH-KDU). Fire Prevention and Emergency Response Plan. Risk Assessment Report $U H-K D U, 5$ March 2019.

5. American College Health Association. ACHA Guidelines: Preparing for COVID-19. Available from:http://www.acha.org/COVID-19. Accessed 15 March 2020.

6. Centers for Disease Control and Prevention (CDC). Quarantine and isolation. Available from:http:// www.cdc.gov/quarantine/index.html.Accessed 24 March 2020.

7. Epidemiology Unit, 2020. Hospital Preparedness for COVID-19 Global Pandemic Circular No. $D D G(M S) 1 / 23 / 2020$ dated 12.04.2020. Available from: http://www.epid. gov.lk/web/index. php?lang=en.Accessed 15 April 2020.

8. Stoller JK. Reflections on leadership in the time of COVID-19 (commentary). BMJ Leader 2020; 0: 1-3. DOI: 10.1136/leader-2020-000244. 